\title{
Structural, Optical and Electrical Properties of Plasma Deposited Thin Films from Hexamethyldisilazane Compound
}

\author{
S. SAlOum* AND B. Alkhaled \\ Atomic Energy Commission of Syria (AECS), Physics Department, P.O. Box 6091, Damascus, Syria \\ (Received May 2, 2010; in final form November 23, 2010)
}

\begin{abstract}
Silicon organic thin films have been prepared by RF hollow cathode plasma chemical vapor deposition system, from hexamethyldisilazane (HMDSN) as the source compound, under different plasma conditions, namely feed gas and applied RF power. The feed gas has been changed from argon to nitrogen, and the power has been varied between $100 \mathrm{~W}$ and $300 \mathrm{~W}$ in $\mathrm{N}_{2}$ /HMDSN plasma. The structural properties of the deposited films have been investigated by the Fourier transform infrared spectroscopy technique. Spectrophotometry measurements have been used to determine films optical constants (refractive index, dielectric constant and energy band gap); in addition, the photoluminescence from these films has been recorded. The electrical resistivity of films has been estimated from the measurements of current-voltage characteristics of deposited thin films. The effect of the different plasma conditions on these structural, optical and electrical properties of the prepared thin films, as well as the correlation between the different properties are reported.
\end{abstract}

PACS: 52.77.Dq, 81.15.Gh, 73.20.At, 78.20.Ci, 84.37.+q

\section{Introduction}

Among variety of silicon-based coatings, amorphous hydrogenated silicon carbonitride $(\mathrm{a}-\mathrm{Si}-\mathrm{C}-\mathrm{N}-\mathrm{H})$ films, owing to their useful properties, have attracted great interest for a variety of technological and industrial applications [1-7], such as surface protection, humidity sensors, hard anti-scratch coatings, diamond-like carbon coatings, and luminescent waveguide structures. This material can be obtained by plasma enhanced chemical vapor deposition (PECVD) technique, using liquid organosilicone vapor sources such as hexamethyldisilazane (HMDSN) $[7,8]$ and tetramethyldisilazane (TMDSN) [9]. HMDSN has been already used in our previous work [10], where the growth rate, gas sensing and surface properties of the deposited films in RF hollow cathode discharge system, have been investigated, under different plasma conditions (changing the feed gas from argon to nitrogen, and varying the applied RF power between $100 \mathrm{~W}$ and $300 \mathrm{~W}$ ).

The present report deals with additional properties of these thin films, important for technological applications. Optical properties (optical constants and photoluminescence property) and electrical properties have been investigated. An attempt to correlate these properties to the chemical bonding structure of the films has been presented.

\section{Experimental procedure}

The experimental setup of the plasma device and the

\footnotetext{
* corresponding author; e-mail: pscientific@aec.org.sy (S. Saloum)
}

deposition system from liquid precursors such as HMDSN are described in detail in our previous works [10-12]. Thin films have been deposited on $n$-type silicon wafers for ex situ analysis of the structure of chemical bonding, where the Fourier transform infrared technique spectrometer (Nicolet $6700 \mathrm{FTIR}$ ) at a resolution of $4 \mathrm{~cm}^{-1}$ has been employed in reflection mode, and for investigating photoluminescence (PL) properties, where the PL spectra were recorded at room temperature using a $1 \mathrm{~m}$ monochromator (SPEX from Jobin Yvon) equipped with a side-on photomultiplier tube R928, and a He-Cd laser (325 $\mathrm{nm}$ excitation wavelength) was used as the excitation source. The films have been deposited also on glass substrates for determining their optical constants (refractive index, absorption coefficient and optical energy band gap) using spectrophotometry measurements as described in [11], and on stainless steel substrates to investigate the electrical properties from current-voltage $(I-V)$ characteristics measurement. Deposition has been carried out under conditions of overall pressure of about $50 \mathrm{~Pa}$ and time of deposition of $20 \mathrm{~min}$, at constant flow rate of HMDSN $\left(Q_{\mathrm{HMDSN}}=12 \mathrm{sccm}(0.09 \mathrm{~g} / \mathrm{min})\right)$ and at four different plasma conditions as follows: S1 (feed gas: argon, $\mathrm{RF}$ power $=100 \mathrm{~W}$ ), S2 (feed gas: nitrogen, $\mathrm{RF}$ power $=100 \mathrm{~W}$ ), S3 (feed gas: nitrogen, $\mathrm{RF}$ power $=200 \mathrm{~W}$ ), $\mathrm{S} 4$ (feed gas: nitrogen, $\mathrm{RF}$ power $=300 \mathrm{~W}$ ); the thicknesses of deposited films were found to be $360 \mathrm{~nm}, 262 \mathrm{~nm}, 398 \mathrm{~nm}$ and $168 \mathrm{~nm}$, respectively [10].

\section{Results and discussion}

\subsection{Structure of chemical bonding}

Figure 1 shows the FTIR reflection spectra for the 


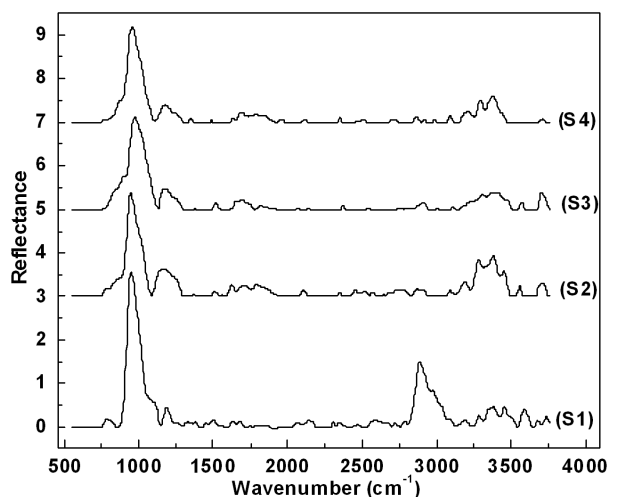

Fig. 1. FTIR reflection spectra of deposited thin films from HMDSN under different plasma conditions S1, S2, S3 and S4 (mentioned in Sect. 2.).

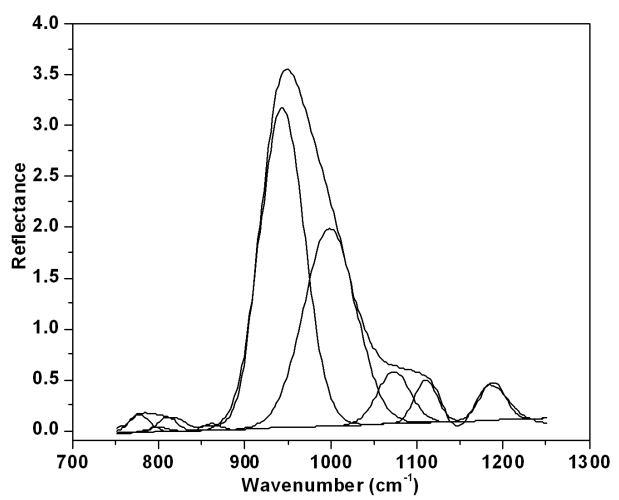

Fig. 2. Deconvolution of the $750-1250 \mathrm{~cm}^{-1}$ IR band for the deposited film at plasma condition S1.

deposited films S1, S2, S3 and S4. For clarity, the curves have been offset vertically. The assignment of particular IR bands was based on the literature data $[2,7,13]$. The film spectra reveal the presence of the following bands:

- A broad intense band in the range of 750-1250 $\mathrm{cm}^{-1}$ including overlapped peaks. Figure 2 shows (as an example) the deconvolution of this band, for the sample S1, into the following Gaussian peaks: $\mathrm{Si}-\mathrm{C}$ stretching mode $\left(770-810 \mathrm{~cm}^{-1}\right)$, $\mathrm{Si}-\mathrm{N}$ stretching mode at about $950 \mathrm{~cm}^{-1}, \mathrm{Si}-\mathrm{O}$ stretching mode (1000-1110 $\mathrm{cm}^{-1}$ ), and $\mathrm{N}-\mathrm{H}$ bending mode of $\mathrm{Si}-\mathrm{NH}-\mathrm{Si}$ and/or Si-NH-C at about $1180 \mathrm{~cm}^{-1}$.

- $\mathrm{CH}_{3}$ asymmetric bending in $\mathrm{Si}-\left(\mathrm{CH}_{3}\right)_{x}$ at around $1490 \mathrm{~cm}^{-1}$.

- $\mathrm{C}=\mathrm{O}$ at around $1700 \mathrm{~cm}^{-1}$.

- $\mathrm{Si}-\mathrm{H}$ stretching in $\mathrm{Si}-\mathrm{H}_{x}$ and/or in $\mathrm{SiO}_{x} \mathrm{~N}_{y} \mathrm{C}_{z}$ at around $2130 \mathrm{~cm}^{-1}$.

- $\mathrm{C}-\mathrm{H}$ stretching bond in $\mathrm{CH}_{x}$ groups at around $2900 \mathrm{~cm}^{-1}$.
- A broad band at around $3380 \mathrm{~cm}^{-1}$, which could originate from the $-\mathrm{NH}$ - stretching mode of $\mathrm{Si}-\mathrm{NH}-\mathrm{Si}$ and/or $\mathrm{Si}-\mathrm{NH}-\mathrm{C}$, but this band may contain also the $\mathrm{O}-\mathrm{H}$ stretching bond in $\mathrm{SiOH}$.

The oxygen contamination, revealed by the contributions of $\mathrm{Si}-\mathrm{O}, \mathrm{C}=\mathrm{O}, \mathrm{O}-\mathrm{H}$ and probably $\mathrm{Si}-\mathrm{OH}$ bands, may originate from different sources such as desorption of residual oxygen from the chamber walls during films deposition, reactions of dangling bonds in the deposit with the atmospheric oxygen or moisture after the film exposure to the ambient environment, and trace impurities in the precursor (HMDSN) and feed gases.

In Table I, the variation of integrated peak intensities of the most intense IR bands for the four studied samples is presented, as well as the ratio between inorganic bands intensities (sum of integrated peaks of $\mathrm{Si}-\mathrm{N}$ and $\mathrm{Si}-\mathrm{O}$ ) and organic integrated peak of $\mathrm{C}-\mathrm{H}$. The comparison between samples $\mathrm{S} 1$ and $\mathrm{S} 2$ demonstrates the effect of changing the feed gas of the plasma, it can be observed that the intensity of $\mathrm{Si}-\mathrm{N}$ band is higher in sample $\mathrm{S} 1$ (argon as feed gas) than in sample S2 (nitrogen as feed gas), which can be attributed to the higher fragmentation of the HMDSN precursor as reported in [10]. The fact that the intensity of $\mathrm{C}-\mathrm{H}$ organic bond decreases rapidly when changing the feed gas from argon to nitrogen indicates the role of nitrogen in decreasing the polymerization of organic radicals, because of the high reactivity of atomic nitrogen with the precursor, which results in breaking these bonds and formation of volatile compounds. The increase of $\mathrm{N}-\mathrm{H}$ band in sample $\mathrm{S} 2$ compared to sample $\mathrm{S} 1$ is accompanied by the vanishing of $\mathrm{Si}-\mathrm{C}$ bond and the rapid decrease of $\mathrm{C}-\mathrm{H}$ intensity band in sample $\mathrm{S} 2$, which may be ascribed to the insertion of $\mathrm{NH}$, formed in the plasma phase through chemical reaction between atomic nitrogen and hydrogen released by the precursor fragmentation, into the $\mathrm{Si}-\mathrm{C}$ bonds and in the segments of the film network [14].

The comparison between samples S2, S3 and S4 shows the effect of applied power on the film structure. It can be observed that, with increasing applied RF power, $\mathrm{Si}-\mathrm{N}$ integrated peak intensity increases, while the intensities of $\mathrm{CH}_{x}$ organic group and $\mathrm{N}-\mathrm{H}$ band decrease. This is in agreement with reported results in $[5,7,15]$, where HMDSN has been polymerized at various applied powers. The increase of $\mathrm{Si}-\mathrm{N}$ band intensity with larger power increase is attributed to the enhancement of collisions of precursor with electrons and active nitrogen species, whose densities were found, from plasma diagnostic, to increase with power increase. The decrease of intensities of $\mathrm{C}-\mathrm{H}$ and $\mathrm{N}-\mathrm{H}$ bands with power increase is attributed to the larger breaking of these bonds in plasma phase at higher RF plasma power as a consequence of inelastic collisions with high energy electrons and nitrogen active species. 
Variation of FTIR analysis as a function of the different plasma deposition conditions.

TABLE I

\begin{tabular}{c|c|c|c|c|c}
\hline \hline $\begin{array}{c}\text { Plasma } \\
\text { conditions }\end{array}$ & $\begin{array}{c}\mathrm{Si- \textrm {N }} \\
\text { peak intensity } \\
\text { [arb.u.] }\end{array}$ & $\begin{array}{c}\mathrm{Si- \textrm {O }} \\
\text { peak intensity } \\
\text { [arb.u.] }\end{array}$ & $\begin{array}{c}\mathrm{N}-\mathrm{H} \\
\text { peak intensity } \\
\text { [arb.u.] }\end{array}$ & $\begin{array}{c}\mathrm{C}-\mathrm{H} \\
\text { peak intensity } \\
\text { [arb.u.] }\end{array}$ & $\begin{array}{c}\text { (Si-N + Si-O)/C-H } \\
\text { peak ratio } \\
\text { [arb.u.] }\end{array}$ \\
\hline S1 & 207 & 140 & 12 & 209 & 1.7 \\
S2 & 145 & 85 & 27 & 12 & 20 \\
S3 & 160 & 120 & 24 & 9 & 31 \\
S4 & 171 & 70 & 13 & 10 & 24
\end{tabular}

\subsection{Optical properties}

\subsubsection{Optical constants}

The spectrophotometry measurements have been carried out in the condition of near normal incidence (angle of incidence $\approx 1.5^{\circ}$ ), and within the spectral range 220-1000 nm with a step of $1 \mathrm{~nm}$. To calculate the absorption coefficient $\alpha(\lambda)$, the following relation was used [11]:

$$
\alpha(\lambda)=\frac{1}{d} \ln \left(\frac{(1-R(\lambda))}{T(\lambda)}\right),
$$

where $d$ is the film thickness, $T$ and $R$ are the transmission and reflection coefficient, respectively. Figure 3 shows the variation of the absorption coefficient for the deposited films under the different plasma conditions. From the absorption coefficient, the extinction coefficient can be deduced as

$$
k(\lambda)=\alpha(\lambda) \frac{\lambda}{4 \pi} .
$$

In the condition of normal incidence, the reflection coefficient $R(\lambda)$ can be written as [11]:

$$
R(\lambda)=\frac{(n(\lambda)-1)^{2}+k(\lambda)^{2}}{(n(\lambda)+1)^{2}+k(\lambda)^{2}},
$$

which enables the determination of the refractive index $n(\lambda)$. The real part of the dielectric constant has been also calculated from the relation

$$
\varepsilon(\lambda)=n^{2}(\lambda)-k^{2}(\lambda) .
$$

The value of the optical energy band gap $E_{\mathrm{g}}$ can be obtained by a plot of $(\alpha h \nu)^{1 / 2}$ vs. $h \nu$ (the Tauc plot) in the region of high absorption and by the extrapolation of the linear region to zero [11]. Figure 4 shows the variation of $(\alpha h \nu)^{1 / 2}$ for the prepared samples.

To elucidate the dependence of both refractive index and dielectric constant on the plasma deposition conditions, we give in Table II, at $\lambda=500 \mathrm{~nm}$, the variations of $n$ and $\varepsilon$, as well as the obtained values of $E_{\mathrm{g}}$ at the different plasma processing conditions. It can be seen that both the refractive index and the dielectric constant have the same trend as a function of plasma deposition conditions, where they are, in sample S1, lower than in sample S2. With increasing applied RF power they show a maximum at $200 \mathrm{~W}$ applied power (sample S3). The refractive index is sensitive to film density and chemical stoichiometry, it increases with the increase of either the film density or the content of Si element in the film [16].

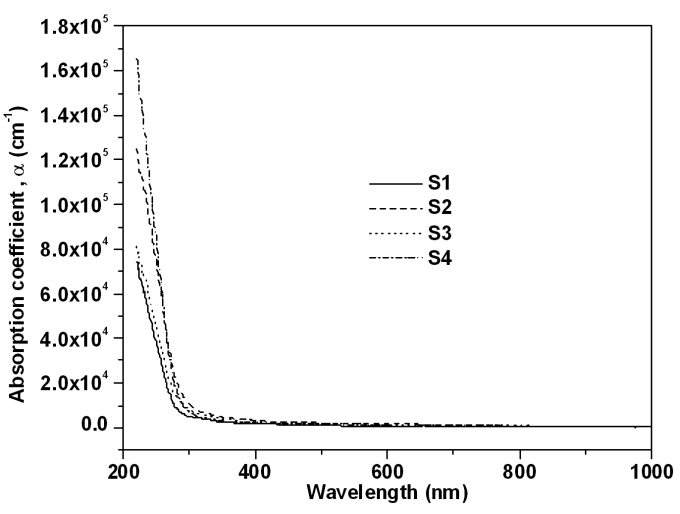

Fig. 3. Variation of absorption coefficient $\alpha(\lambda)$ vs. wavelength for films deposited under the different plasma conditions.

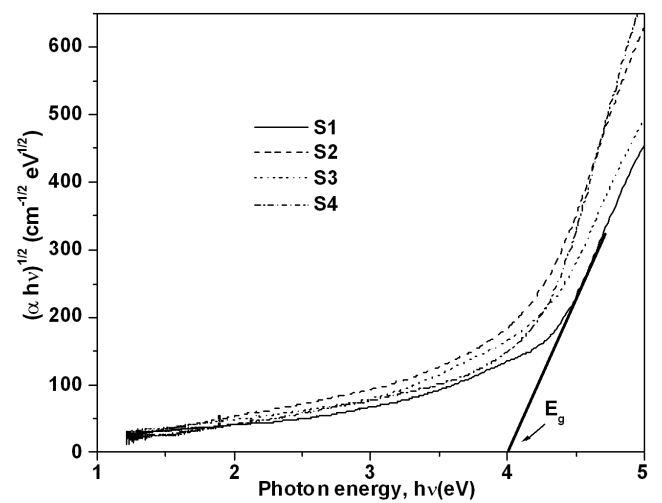

Fig. 4. Variation of $(\alpha h \nu)^{1 / 2}$ vs. the photon energy $h \nu$ for films deposited under the different plasma conditions.

Comparing the obtained behavior of refractive index with that of the ratio $(\mathrm{Si}-\mathrm{N}+\mathrm{Si}-\mathrm{O}) / \mathrm{C}-\mathrm{H}$ (Table $\mathrm{II})$, one can observe the good correlation between them.

The behavior of refractive index can also be related to film morphology, where $n$ increases when deposition conditions produce less porous and more compact layer [11]. The obtained morphological results of deposited films, which are reported in our previous work [10], show that the refractive index increases with the decrease of both 
grains size and surface roughness that is when the grains of film surface are small and more densely packed. In regard to the behavior of optical energy band gap, Table II shows that $E_{\mathrm{g}}$ decreases between $\mathrm{S} 1$ and S3, and then increases, where a minimum occurs in sample S3. The values are in the range of the reported ones in the literature $[7,17]$, which fall in the range $2-5 \mathrm{eV}$. The decrease of $E_{\mathrm{g}}$ can be attributed to the increase of the dangling bonds created in the film during the deposition process [11].

TABLE II

Variation of optical constants of films deposited at different plasma conditions.

\begin{tabular}{c|c|c|c}
\hline \hline $\begin{array}{c}\text { Plasma } \\
\text { conditions }\end{array}$ & $\begin{array}{c}\text { Refractive } \\
\text { index, } n\end{array}$ & $\begin{array}{c}\text { Dielectric } \\
\text { constant, } \varepsilon\end{array}$ & $\begin{array}{c}\text { Optical band } \\
\text { gap, } E_{\mathrm{g}}[\mathrm{eV}]\end{array}$ \\
\hline $\mathrm{S} 1$ & $1.587 \pm 0.002$ & $2.738 \pm 0.003$ & $4.00 \pm 0.01$ \\
$\mathrm{~S} 2$ & $1.692 \pm 0.002$ & $2.877 \pm 0.003$ & $3.88 \pm 0.01$ \\
$\mathrm{~S} 3$ & $1.697 \pm 0.002$ & $2.895 \pm 0.003$ & $3.86 \pm 0.01$ \\
$\mathrm{~S} 4$ & $1.633 \pm 0.002$ & $2.821 \pm 0.003$ & $4.05 \pm 0.01$
\end{tabular}

As can be seen from Table I, the ratio between inorganic and organic IR bond peak intensities has a maximum at plasma condition S3, which means that the deposition of inorganic molecules, with unsaturated bonds on the substrate increases. These unsaturated bonds are responsible for the formation of localized defects in the film; such defects increase the density of localized states in the band structure [18].

\subsubsection{Photoluminescence properties}

Figure 5 represents the room temperature photoluminescence (PL) spectra of the deposited thin films on $\mathrm{Si}$ wafers under the different plasma conditions S1, S2, S3 and S4. The peaks of PL band centers of the deposited films are situated at wavelengths of about $495 \mathrm{~nm}$, $548 \mathrm{~nm}, 565 \mathrm{~nm}$ and $541 \mathrm{~nm}$, respectively. The intensity of the PL peak varies clearly with the change of plasma conditions; its lowest value has been found at S1 and the highest one at S3.

In general, the observed visible luminescence in such plasma deposited films could be related to the existed chemical complexes in the film, which contains $\mathrm{Si}, \mathrm{O}, \mathrm{N}$, $\mathrm{H}$ and $\mathrm{C}$ elements [19, 20]. Different authors explored the PL from similar films. Rüter et al. [21] prepared luminescent waveguiding layer structures, in the spectral range of the luminescence emission (400-550 nm), on the bases of amorphous silicon-carbon based thin films deposited in a microwave plasma reactor, using organosilane vapors from liquid sources such as HMDSN. Seekamp et al. [22] investigated the PL properties of plasma deposited films from liquid organosilicone precursors such as HMDS and HMDSN, where they found that the PL maximum varies between $490 \mathrm{~nm}$ and $410 \mathrm{~nm}$, and attributed this PL to the existence of different chemical structures in the precursor such as $\mathrm{Si}-\left(\mathrm{CH}_{3}\right)_{2}, \mathrm{Si}-\left(\mathrm{CH}_{3}\right)_{3}$ and $\mathrm{Si}-\mathrm{CH}_{2}-\mathrm{Si}$.

For our present results, the PL peak intensity seems to be well correlated to the ratio of IR band intensities $(\mathrm{Si}-\mathrm{N}+\mathrm{Si}-\mathrm{O}) / \mathrm{C}-\mathrm{H}$ (Table I), while its maximum blue

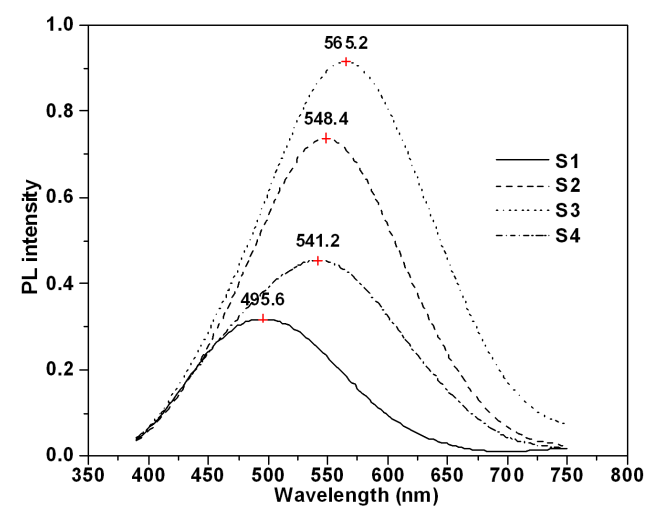

Fig. 5. Photoluminescence spectra for films deposited under the different plasma conditions.

shift (at S1) can be related to the excess of $\mathrm{Si}-\mathrm{N}$ and $\mathrm{Si}-\mathrm{O}$ contents in the film.

It is important to note that the PL intensity does not have a clear dependence on film thickness. Indeed, the penetration depth (the inverse of the absorption coefficient, $\alpha)$ of laser light $(325 \mathrm{~nm})$ has been estimated from the spectrophotometry measurements in the previous Sect. 3.2.1, and found to be more than $1500 \mathrm{~nm}$ for all samples, that means it is much larger than the films thicknesses. Hence, instead of an influence of the excitation thickness, a dependence of the structure variation on the thickness is a more favorable reason for the luminescence behavior [20].

To have an idea about the dependence of PL intensity on the absorbance $(\alpha d)$ of films, the absorbance of samples S1, S2, S3 and S4 has been calculated, at PL peak wavelength, and found to be $3.6 \times 10^{-9}, 4.5 \times 10^{-9}$, $5.1 \times 10^{-9}$ and $1.8 \times 10^{-9}$, respectively. From Fig. 5, one can observe the good correlation between the trends of both PL peak intensity and the absorbance for the samples S2, S3 and S4, where the maximum PL intensity and the maximum of the absorbance occur at the same sample S3.

\subsection{Electrical properties}

Besides the optical properties, the electrical properties are also an important aspect of the technological applications of plasma polymerized HMDSN thin films. These properties have been investigated through the measurement of current-voltage $(I-V)$ characteristics, as shown in Fig. 6. It can be observed that the thin films exhibit approximately an ohmic $I-V$ relationship, and the lowest forward current is obtained for sample S4. The bulk resistivity $\rho[\Omega \mathrm{cm}]$ has been estimated, too, and the values are presented in the inset of Fig. 6 , the films show relatively high insulation property $\left(\rho \approx 10^{13}-10^{14} \Omega \mathrm{cm}\right)$, sample S4 has a resistivity higher than that of other samples of about one order of magnitude. Comparing the behavior of the films resistivity with FTIR analysis as a function of deposition conditions, one can conclude that there is no evident correlation between them, 


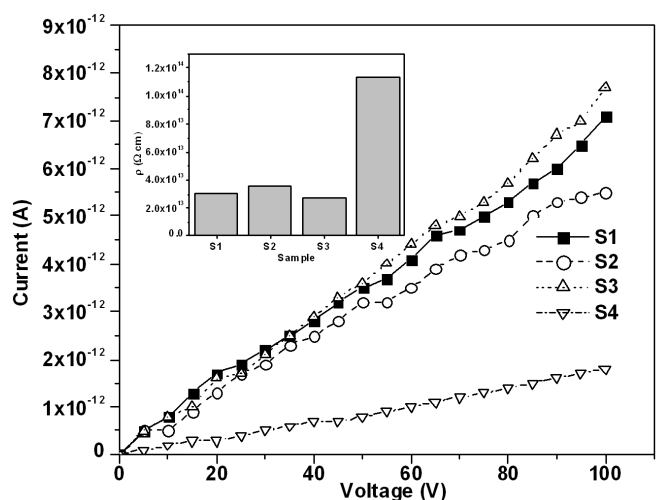

Fig. 6. Current-voltage characteristics of films deposited under the different plasma conditions. The inset shows the variation of the electrical resistivity of films.

while it can be noticed that the resistivity scales inversely with film thickness. These important electrical properties (high resistivity $\approx 10^{13} \Omega \mathrm{cm}$, and dielectric constant of about 2.8) suggest that such films are candidate materials for a number of advanced technological applications, in particular as interlevel insulators with a low permittivity coefficient for next-generation giga- and terabit silicon memory circuits [17].

\section{Conclusions}

Plasma-polymerized thin films are obtained from HMDSN compound source in a RF plasma system, under different plasma conditions of feed gas and applied RF power. The effect of changing plasma conditions on the structural, optical and electrical properties of the prepared thin films has been investigated. It has been found that changing the feed gas from a rare gas (argon) to a reactive molecular gas (nitrogen) implies an enhancement of inorganic character of the films, which is accompanied with an increase of refractive index (from 1.587 to 1.692 ), dielectric constant (from 2.738 to 2.877) and PL intensity; and a decrease of energy band gap (from $4 \mathrm{eV}$ to $3.88 \mathrm{eV}$ ). In $\mathrm{N}_{2} / \mathrm{HMDSN}$ plasma deposition environment, the applied power has been changed from $100 \mathrm{~W}$ to $300 \mathrm{~W}$, and the obtained films showed a maximum at $200 \mathrm{~W}$ of the IR band intensity ratio $((\mathrm{Si}-\mathrm{N}+\mathrm{Si}-\mathrm{O}) / \mathrm{C}-\mathrm{H})$, which corresponds to a maximum of refractive index, dielectric constant, optical absorbance and PL intensity, and to a minimum of energy band gap. The prepared films exhibit relatively high electrical resistivity $\left(10^{13}-10^{14} \Omega \mathrm{cm}\right)$, it has been found to be inversely proportional to film thickness. This work shows that plasma-polymerized HMDSN thin films have attractive properties through their PL emission and their high resistivity for possible optoelectronics and microelectronics applications.

\section{Acknowledgments}

The authors would like to thank Prof. I. Othman, Director General of AECS, for encouragement and permanent support.

\section{References}

[1] I. Blaszczyk-Lezak, A.M. Wrobel, D.M. Bielinski, Thin Solid Films 497, 35 (2006).

[2] I. Blaszczyk-Lezak, A.M. Wrobel, T. Aoki, Y. Nakanishi, I. Kucinska, A. Tracz, Thin Solid Films 497, 24 (2006).

[3] D. Probst, H. Hoche, Y. Zhou, R. Hauser, T. Stelzner, H. Scheerer, E. Broszeit, C. Berger, R. Riedel, H. Stafast, E. Koke, Surf. Coat. Technol. 200, 355 (2005).

[4] L.-Y. Chen, F.C.-N. Hong, Diamond Relat. Mater. 12, 968 (2003).

[5] F. Kraus, S. Cruz, J. Muller, Sensors Actuators B 88, 300 (2003).

[6] W. Bauhofer, D. Ruter, Appl. Surf. Sci. 102, 319 (1996).

[7] E. Vassallo, A. Cremona, F. Ghezzi, F. Dellera, L. Laguardia, G. Ambrosone, U. Coscia, Appl. Surf. Sci. 252, 7993 (2006).

[8] H.D. Kuo, D.G. Yang, Thin Solid Films 374, 92 (2000).

[9] A.M. Wrobel, I. Blaszczyk-Lezak, A. Walkiewicz-Pietrzykowska, D.M. Bielinski, T. Aoki, Y. Hatanaka, J. Electrochem. Soc. 151, C723 (2004).

[10] S. Saloum, B. Alkhaled, Acta Phys. Pol. A 117, 484 (2010).

[11] S. Saloum, M. Naddaf, Vacuum 82, 55 (2007).

[12] S. Saloum, M. Naddaf, Vacuum 82, 66 (2007).

[13] F. Fracassi, R. Lamendola, Plasma. Polym. 2, 25 (1997).

[14] A.M. Wrobel, I. Blaszczyk, A. Walkiewicz-Pietrzykowska, A. Tracz, J.E. Klemberg-Sapieha, T. Aoki, Y.J. Hatanaka, Mater. Chem. 13, 731 (2003).

[15] M.T. Kim, J. Lee, Thin Solid Films 303, 173 (1997).

[16] A.G. Erlat, B.-C. Wang, R.J. Spontak, J. Matter. Res. 15, 704 (2000).

[17] T.P. Smirnova, A.M. Badalyan, V.O. Borisov, V.V. Kaichev, L.F. Bakhturova, V.N. Kichai, V.I. Rakhlin, B.A. Shainyan, Inorg. Mater. 41, 706 (2005).

[18] L.I. Soliman, Fizika A 11, 91 (2002).

[19] B.H. Augustine, E.A. Irene, Y.J. He, K.J. Price, L.E. McNeil, K.N. Christensen, D.M. Maher, J. Appl. Phys. 78, 4020 (1995).

[20] M. Naddaf, S. Saloum, H. Hamadeh, J. Phys. D, Appl. Phys. 40, 4015 (2007).

[21] D. Rüter, S. Rolf, W. Bauhofer, Appl. Phys. Lett. 67, 149 (1995).

[22] J. Seekamp, J. Niemann, W. Bauhofer, J. Non-Cryst. Solids 266-269, 749 (2000). 